\title{
O alienígena e o embate entre Veja versus MEC*
}

\author{
El alienígena y la pelea entre la revista Veja \\ y el Ministerio de Educación de Brasil (MEC)
}

\author{
The alien and the clash between Veja \\ and the Brazilian Ministry of Education (MEC)
}

\author{
Adriana Santiago Dantas**
}

Palavras chave:

Resumo:

Sociolinguística

Foucault

MEC

Veja
Este ensaio tem por objetivo demonstrar o embate ocorrido na mídia brasileira por causa da distribuição pelo Ministério da Educação (MEC) de um livro didático para educação de jovens e adultos. Como representante midiática contrária à proposta do livro foi escolhida uma edição da revista Veja. Para análise, foi realizada uma contextualização da Sociolinguística a partir da metáfora do alienígena, representando o argumento do MEC; e a explicitação do argumento da revista Veja que teve como pano de fundo a defesa da "cultura". A partir desta análise, foram utilizados os conceitos da Ordem do Discurso de Foucault para concluir que o embate representou uma disputa pela "vontade de verdade", segundo conceitua o autor. 


\section{Resumen:}

Este ensayo tiene por objetivo demostrar la pelea ocurrida en la media brasileña a causa de la distribución por el Ministerio de Educación (MEC) de un libro didáctico para la educación de jóvenes y adultos. Como representante mediática contraria a la propuesta del libro fue elegida una edición de la revista Veja. Para el análisis, fue realizada una contextualización de la Sociolingüística a base de la metáfora del alienígena, representando el argumento del MEC; y la explicitación del argumento de la revista Veja, el que tuvo como trasfondo la defensa de la "cultura". A partir de esto, fueron utilizados los conceptos del Orden del Discurso de Foucault para concluir que la pelea representó una disputa por la "voluntad de verdad", según conceptúa el autor.

\section{Palabras clave:}

Sociolingüística

Foucault

MEC

Veja

\section{Keywords:}

Sociolinguistics

Foucault

MEC

Veja

\section{Abstract:}

This essay aims to demonstrate the conflict that occurred in the Brazilian media as a result of the distribution of a textbook for youth and adult education by the Ministry of Education (MEC). An issue of Veja magazine was chosen to represent the opposition to the book in the media. For the analysis, a sociolinguistic contextualization was carried out based on the alien metaphor, representing the argument of MEC; and the clarification of Veja's argument which had a backdrop in defense of "culture". From this analysis, the concepts of Foucault's Order of Discourse were utilized to conclude that the clash represented a battle over the "will of truth", according to the author. 


\section{0 alienígena e o embate entre Veja versus MEC}

O livro didático Por uma vida meIhor distribuído pelo Ministério da Educação (MEC) causou uma grande polêmica na sociedade a partir da mídia brasileira, por ter como referencial teórico estudos da Sociolinguística. Este ensaio tem por objetivo discutir um momento histórico na educação brasileira à luz dos Estudos Culturais usando a análise do discurso a partir de Michel Foucault. Pretende-se demonstrar ao longo do texto como essa polêmica é uma disputa pela "vontade de verdade", conceito foucaultiano, e também como se dá essa disputa. Para representar parte da polêmica, foi escolhida uma edição da revista Veja por sua abrangência nacional como "formadora de opinião". O artigo está dividido nas seguintes partes: 1. o alienígena, uma metáfora sobre os estudos linguísticos para discutir a questão do MEC versus Veja; 2. o MEC, comentário sobre o livro e seu referencial teórico; 3. a Veja, o discurso da revista sobre a polêmica; 4. Nos Estudos Culturais, a análise a partir da abordagem dos Estudos Culturais e 5. Considerações Finais.

\section{1 - O ALIENÍGENA}

Suponha que um alienígena especialista em língua aterrissasse na Terra sem saber nada sobre como os terráqueos se organizam em sociedade. Especificamente, sua nave espacial chega ao Brasil. Esse alienígena entende que língua é um código convencional de comunicação que os terráqueos usam para sua interação social. Com todos os seus recursos tecnológicos, ele descobre que dentre os muitos idiomas falados no Brasil, o de maior incidência é o português brasileiro. Em sua análise, ele percebe que há variações em todo o território brasileiro que ele previamente delimitou para a sua análise.
Descobriu alguns livros que normatizavam uma forma de falar da qual nenhum falante se apropriava totalmente. Havia alguns poucos que se aproximavam daqueles livros, mas ele decidiu desconsiderar esse fato, visto que a maioria dos brasileiros utilizavam uma outra variação da língua brasileira. Por exemplo, o alienígena constata que sintaticamente a maioria dos falantes usa o plural apenas no artigo e não no substantivo e no verbo que o acompanha: "os menino canta bem". E um número menor de brasileiros fala: "os meninos cantam bem". E o curioso é que as duas frases tinham o mesmo sentido. Por essas e outras análises, ele resolve usar a forma que a maioria dos brasileiros usa para se comunicar e acha até mais interessante e se pergunta: por que esses poucos colocam o plural no substantivo e verbo se o artigo já define isso? Assim, ele termina sua análise com essa pergunta em mente.

Como falantes do português, sabemos que a lógica do alienígena não funcionaria na sociedade se ele desejasse usar uma variação da língua mais aceita socialmente. Neste ponto, não indico como lógica o uso da maior variante linguística, mas indico a lógica de pensar que a maneira de falar da maioria deveria ser a mais aceita. Essa aceitação é tão estranha socialmente que para um leigo em Linguística entendê-la é preciso trazer esta metáfora esdrúxula, para saber em que local o uso dessa variação faz algum sentido.

O pai da Linguística Ferdinad Saussure ${ }^{1}$ instaurou uma nova abordagem para se estudar a língua ao descrever suas estruturas internas, a sincronia, e não apenas sua evolução ao longo do tempo, a diacronia, como eram os estudos sobre a Língua desde então. Fundou-se assim o Estruturalismo que historicamente se situa no Modernismo quando as Ciências Humanas se propuseram a produzir conhecimento científico com ferramentas parecidas das Ciências Naturais. Dentre as muitas críticas que 
a abordagem da Linguística Estruturalista recebeu dos pós-modernos e pós-estruturalistas, a metáfora do alienígena poderia representar uma delas. Isto é, o alienígena descreve a estrutura da língua sem considerar outros aspectos como a situação social, as circunstâncias em que ocorrem os enunciados, dentre outros. No entanto, esta metáfora pode servir também para um aspecto positivo na discussão aqui proposta: o do distanciamento social e político para entender o funcionamento da língua. A metáfora do alienígena tem esta função, representaria a "neutralidade" do funcionamento da língua a partir de sua estrutura interna representada pelo Estruturalismo. Esse entendimento é importante, pois a partir dessa abordagem é que foi possível, mais tarde, explicitar que os julgamentos de valor de certo e errado nos estudos da linguagem eram de outra ordem e não estrutural. Parte dessa denúncia se dá nos estudos da Sociolinguística. Afirmo, assim, que o estruturalismo e pós-estruturalismo não possuem apenas uma relação dialética, mas também de complementaridade.

Foucault (2009), de escola pós-estruturalista, afirma que há determinados procedimentos no discurso que devem ser considerados, como o de exclusão. Dentro da exclusão, o autor indica seus desdobramentos como a interdição ${ }^{2}$, que dita que nem tudo pode ser dito. Como no nosso caso, a aceitação da variação linguística da maioria só pode ser dita por um alienígena. $\mathrm{O}$ autor também desdobra a interdição pela vontade de verdade, que tem por trás de si o desejo e o poder. Essa explicação foucaultiana está profundamente ligada com o susto social que esse alienígena teria ao criar para si essa lógica para o português que será melhor explicitado ao longo do ensaio.

Assim, os conceitos desenvolvidos por Foucault serão usados como referencial teórico para concluir a argumentação a respeito da polêmica que envolveu o livro didático distribuído pelo MEC. Parte deste livro aborda o ensino da Língua Portuguesa a partir do ponto de vista da Sociolinguística, que parte do conhecimento científico estrutural da Língua para explicitar os desdobramentos sociais sofridos pelas variações linguísticas do português brasileiro.

\section{2 - O MEC}

O livro didático Por uma vida meIhor destinado ao Ensino de Jovens e Adultos (EJA) distribuído pelo Ministério da Educação (MEC) ficou nacionalmente conhecido devido à polêmica levantada pela mídia sobre o conteúdo "não educativo" que este trazia. O Ministério da Educação (BRASIL, 2011) defendeu sua posição no sítio oficial da instituição. O então ministro da educação Fernando Haddad defendeu a escolha ao informar que foram especialistas de universidades públicas que derem os pareceres a respeito do livro didático. Na mídia, apareceu apenas o texto fora do contexto e neste último, os especialistas têm toda uma construção teórica que leva para uma questão política e ideológica que tem como pano de fundo o poder, o qual é tomado neste ensaio como conceitua Foucault no discurso. Isto é importante salientar, pois o embate se dá nesse nível e não no que apareceu no discurso midiático.

Façamos então parte da reconstrução teórica. Especificamente, o capítulo 1 denominado "Escrever é diferente de falar" (2011) do livro didático foi o alvo dos ataques por trazer impresso frases que não correspondem às regras das gramáticas normativas e sim da fala popular. Frases estas que o alienígena constataria que boa parte da população brasileira domina.

Nesta parte, ensina-se sobre a diferença entre a escrita e fala, introduzindo o conceito de variação linguística estudado dentro do escopo da Sociolinguística. O livro é destinado ao EJA, portanto não 
tem como alvo o público infantil e sim jovens de 15 anos, adultos e idosos. Devido a este contexto específico, parte-se do pressuposto no livro de que as pessoas de destino não dominariam a norma culta, mas outra variante, a norma popular. Há uma discussão no livro a respeito dessas duas variantes, que toma a questão do poder como peça-chave da legitimação da norma culta em detrimento da popular:

Essas variantes também podem ser de origem social. As classes sociais menos escolarizadas usam uma variante da língua diferente da usada pelas classes sociais que têm mais escolarização. Por uma questão de prestígio - vale lembrar que a língua é um instrumento de poder -, essa segunda variante é chamada de variedade culta ou norma culta, enquanto a primeira é denominada variedade popular ou norma popular.

Contudo, é importante saber o seguinte: as duas variantes são eficientes como meios de comunicação. A classe dominante utiliza a norma culta principalmente por ter maior acesso à escolaridade e por seu uso ser um sinal de prestígio. Nesse sentido, é comum que se atribua um preconceito social em relação à variante popular, usada pela maioria dos brasileiros. (idem, p.12)

$\mathrm{O}$ autor que desenvolveu o conceito "preconceito lingüístico" utilizado no livro didático foi o professor da Universidade de Brasília, doutor em Filologia, Marcos Bagno. O autor publicou o livro Preconceito Lingüístico. O que é, como se faz (BAGNO, 1999) e em pouco menos de 10 anos, chegou à $50^{a}$ edição em 2008. Na introdução da $50^{a}$ edição, o autor faz a seguinte hipótese para explicar o sucesso da publicação:

De fato, parece que existia uma lacuna importante na bibliografia brasileira sobre questões de linguagem: livros escritos de forma acessível aos não especialistas (e a futuros especialistas) que explicitassem, com a máxima franqueza, opiniões divergentes da ideologia linguística dominante em nossa cultura - uma ideologia antibrasileira, repressora e autoritária, assumida e divulgada por gente que vê "erros" por todo lado e que acredita no mito da existência, num passado longínquo, de que uma "época de ouro" da língua, quando todos falavam "certo" e ninguém "corrompia" a mística "língua de Camões" (Idem, p. 09-10)

Para Bagno, o que determina o "certo" e o "errado" na língua é de ordem ideológico-político e não estrutural. Ele levanta a questão de que se toma a língua incorruptível em momento histórico e a partir daí, têm-se esse modelo como o padrão. Para o autor, língua pura é um mito. Se pensarmos na linha diacrônica da língua, tenho que concordar com o autor, pois o português brasileiro já é uma variação do português europeu. Este, por sua vez, foi uma mudança que surgiu a partir do latim, não do clássico e sim das diversas variações do latim vulgar. Nossa língua sofreu variação linguística até ocorrer a mudança como ilustra o nosso caso: latim clássico $\rightarrow$ latim vulgar $\rightarrow$ português. Processo semeIhante aconteceu com outras línguas românicas como o francês e o espanhol que também vieram da norma menos valorizada do Latim, o vulgar que, por sua vez, foi uma variação do latim clássico. (ILARI, 1999). E no momento sincrônico em que o Latim clássico e vulgar eram falados, este último sofreu o que Marcos Bagno chama hoje de preconceito lingüístico. Discutir a língua dessa forma, segundo o autor, trouxe muita aceitação do público, mas também:

É claro que também chegaram (e continuam chegando) reações grosseiras e furiosas da parte de gente que não esconde seu ideário político conservador, elitista e autoritário. (...) É claro que o li- 
vro podia e continua podendo ser criticado, mas a crítica perde todo o seu efeito saudável quando se transforma em ataque pessoal e deixa explícito o sentimento da intolerância, a maior inimiga da humanidade em todos os tempos, e hoje mais que nunca. (op. cit., p. 10)

Por isso, Bagno ressalta que o que está por trás desta questão, não é a estrutura da língua e sim uma "ideologia linguística dominante", em outras palavras, o poder. Quando o debate em torno da questão torna-se pessoal e não acadêmico, a crítica acaba não tendo um bom efeito demonstrando o que ele defende: o preconceito lingüístico de ordem ideológico-político que tem como motor o conservadorismo de seu status quo. O livro didático do MEC ousou em romper com esse conservadorismo, imprimindo em suas páginas construções tidas como "erradas" independentemente do contexto em que se aborda a questão. Mesmo explicado este posicionamento teórico no capítulo em que as frases foram impressas praticamente não se levantou esse debate, a crítica mostrou toda a intolerância a respeito do assunto.

Assim, tendo como pano de fundo essa construção teórica é que se pode entender a escolha dos especialistas do MEC em distribuir esse livro didático dentre as pessoas que estão fazendo parte da Educação Básica numa fase adulta da vida. Pouco apareceu na mídia essa construção teórica e sim a discussão de um livro didático ter frases escritas de forma "errada". Para ilustrar como se deu essa construção por parte midiática foi escolhida uma revista nacional de grande porte para representar parte dessa vertente do embate, a revista Veja.

\section{3 - A VEJA}

A polêmica em torno do livro didático do MEC alcançou várias vertentes midiáticas: jornais impressos, revistas, matérias televisivas e internet. Para este ensaio foi escolhida como um exemplo da repercussão a revista Veja por se posicionar claramente contrária à distribuição do livro, permitindo uma análise mais contundente do embate. Evidentemente, ela não é representativa da opinião total da mídia do Brasil, mas por ter um posicionamento contrário e emblemático, por ser uma revista de grande porte de alcance nacional, a edição de 25 de maio de 2011 é uma boa escolha para analisar como se dá o embate aqui proposto a ser discutido. Nesta edição, a revista destacou diretamente três artigos sobre o tema. $\mathrm{O}$ primeiro foi a seção Carta ao Leitor, com o título "Preconceito Contra a Educação" (VEJA, 2011, p.14). O segundo destaque foi um artigo de Lya Luft (2011, p.26) intitulado "Chancela para a ignorância". Por fim, o artigo principal chamado "Os adversários do bom português" (BETTI ; LIMA, 2011, p. 86-87).

$\mathrm{Na}$ seção "Preconceito contra a educação", o autor começa o texto informando que o livro fornecido pelo MEC prega que não há certo e o errado no emprego da língua, defendendo que a norma culta é mais uma forma de emprego da língua. O autor afirma que a "norma culta urbana" é categoricamente entendida como "o modo correto de falar e escrever". Ele também argumenta que comunicar-se eficiente entre os "incultos" (sic) não está em questão e sim a falta de inclusão desses mesmo "incultos" à filosofia, ciência e literatura só proporcionada pela produção do "universo lingüístico" que a norma culta urbana tem a possibilidade de realizar. Para o autor, há uma desqualificação das regras gramaticais do "bom português". Por trás, de tudo isso, segundo o autor, há uma ideologia perversa de não permitir o acesso a educação àqueles que mais precisam, impedindo-os que alcançarem uma vida melhor. $\mathrm{O}$ autor cita que este tipo de estudo faz parte da Sociolinguística, mas 
de maneira secundária, no sentido de pouca relevância, e que nunca deveria ter saído do "porão acadêmico".

Lya Luft, no seu ensaio, indica seu assombro em verificar que o livro do MEC "promove o não ensino da língua-padrão, que todos os brasileiros, dos mais simples aos mais sofisticados, têm direito de conhecer e usar". Outro argumento que a autora usa é de que falar em "preconceito lingüístico" leva à conclusão de que não se deve ensinar nada a ninguém para que não se fique humilhado e não deseje melhorar. A autora concorda que há variedades do uso da linguagem de acordo com a situação, Luft chama isso de "adequação". O problema para a autora é ignorar a língua-padrão, pois todos têm o "direito" de conhecê-la. Ela chama isso de discriminação, pois coloca os menos privilegiados num lugar de permanência de seu lugar, sem acesso ao conhecimento. A autora termina seu artigo amenizando a responsabilidade do MEC, pois entende que diante de "montanha de trabalhos que ali se empenham" o livro deve ter passado despercebido. Mas uma vez notado o problema, cumpre as autoridades de retirá-lo de circulação.

O artigo principal intitulado "Os adversários do bom português" tem como subtítulo "doutrinar crianças com a tese absurda de que não existe certo ou errado no uso da língua é afastá-las do que elas mais precisam para ascender na vida". Não só nos títulos, mas todo o artigo é caracterizado por adjetivos binários - bom e ruim - demonstrando a parcialidade da opinião da revista, a respeito da Sociolinguística desqualificando-a para atingir a escolha do MEC deste tipo de referencial teórico. O texto demonstra os ânimos alterados provocados pela escolha do MEC. O conhecimento dos estudos sociolingüísticos é chamado de doutrinação, chamada de tese absurda. Também argumenta no sentido de que o conhecimento sociolinguístico impede as pessoas de ascensão na vida.
O texto do artigo principal começa no tom apaixonado de perplexidade para explicar que o assunto do artigo é o livro didático Por uma vida melhor. O livro não é destinado para crianças, como informa - subtítulo, indicando uma manipulação estilística para aumentar o teor emocional da chamada. Depois de expor a proposta do livro negativamente, as autoras se surpreendem que a proposta da "ignorância prospera sobre a chancela oficial" em uma crítica direta ao MEC. Depois desqualifica a Sociolinguística de forma pessoalizada "um dos expoentes dos talibãs da linguística no Brasil é um certo Marcos Bagno, professor da Universidade de Brasília (UnB), hoje o grande madraçal da ortodoxia dessa estupidez" (idem, p 87). As autoras se utilizam de figuras orientais de forma negativa para fazer o ataque pessoal, usando a palavra talibã e madraçal, como bem previu Bagno na introdução do seu livro. Depois chama de escandaloso o fato de a população brasileira pagar tanto imposto e um dos seus fins ser o de financiar estudiosos como Marcos Bagno. Por fim, chama o processo de crime reescrevendo o depoimento de uma procuradora que concorda com o posicionamento da revista.

Assim, a crítica da revista fica no campo político-ideológico e pessoal e não às conclusões dos estudos científicos da Sociolinguística. Esta, quando abordada, foi pessoalizada em Marcos Bagno, qualificando seus estudos de secundário, sem de fato explicar a teoria que referencia os conceitos deste autor. Há uma "política do silêncio" como conceitua Orlandi (1990, p.49-52) que proíbe alguns sentidos de circularem porque a linguagem tem uma direção política. É um silêncio que não é apenas negação ou ausência de linguagem, mas um fato histórico, que indica significação. Assim, o silêncio da revista é uma estratégia de significação. Ignora-se a discussão, parte-se para a desqualificação usando como argumento que a detenção da norma culta pode libertar os 
"incultos" dos males sociais. A partir daí é possível trazer a discussão para o campo dos Estudos Culturais.

\section{4 - NOS ESTUDOS CULTURAIS}

A dicotomia do "Bom Português" e do "Português Ruim" pode ser comparada à dicotomia "Cultura Erudita" e "Cultura Popular". Ao fazer essa comparação, tenho como objetivo situá-la no contexto dos Estudos Culturais.

Stuart Hall (2009) indica o período 1957-1963 como o "momento propício" de ruptura para um novo paradigma de se explicar a História e de emergência dos Estudos Culturais tendo como marca a publicação dos livros As utilizações da cultura de Hoggar em 1957, Cultura e Sociedade de Williams em 1958 e A formação da classe operária de Thompson em 1963. Nestas obras, "a 'cultura' era o local de convergência" (idem, p.126) a partir de uma abordagem diferente, caracterizando pois o momento de ruptura.

Este momento é propício porque permitiu mudanças ao lidar com uma antiga problemática, a questão da cultura e que tipos de respostas foram dadas por estes autores que trouxeram à baila novos paradigmas epistemológicos tanto para a história, sociologia, as artes, etc. De forma geral, as décadas de 1950 e 1960 serão tomadas como esse momento histórico nas Ciências Humanas e Sociais propício para algumas mudanças epistemológicas.

Para Hall, a obra de Hoggar trouxe um desvio radical para a dicotomia alta e baixa cultura ao ler a cultura da classe trabalhadora para sua metodologia de análise. Já Williams definiu uma nova tradição em instituir a unidade entre esses dois conceitos, sociedade e cultura. O trabalho de Williams analisou diversos autores considerados de "alta cultura", a partir de suas obras e reconceitou o que seria "cultura", questionando o paradigma ideologicamen- te construído de "alta cultura". E por fim, Thompson estava utilizando a história de movimentos populares da Inglaterra, considerados como bárbaros, para demonstrar que a classe operária foi formada a partir destas pessoas, rompendo com o paradigma marxista de quando foi formada a classe operária inglesa, destacando questões culturais para a historiografia e do agenciamento da classe não hegemônica. Estes autores, de certa forma, trouxeram o não hegemônico, para a ordem de discussão a partir da cultura. E essa foi uma grande contribuição para as Ciências Humanas e Sociais porque promoveu um tempo de repensar o que já estava sedimentado.

Ao fazer esse resgate histórico, tenho como objetivo resgatar uma característica singular dos Estudos Culturais europeus: o de desmistificação do estandardizado pelo senso comum como verdade ou em outras palavras, esse estandardizado é uma ideologia que se tornou "verdade". Essa ruptura do que é ou não "alta cultura" é bem propícia para analisar essa situação específica brasileira em relação o que é ou não "bom português" para chegar à conclusão do que está em jogo nesse embate é de ordem ideológica se valendo de uma manifestação estrutural da língua, por isso recorro à metáfora do alienígena para entendê-la como ferramenta para contribuir na análise. Para se distanciar do senso comum é necessário um olhar alienígena também.

Nesse ponto, chega-se ao que Foucault chamou de vontade de verdade no discurso. Para defender a sua vontade de verdade, a revista Veja, nos três artigos, utiliza como um dos argumentos discursivos o do direito ao acesso à norma culta. Segundo os autores, esse acesso é importante, pois é através dele que se consegue o sucesso profissional, além de proporcionar as condições de conhecer produções da "norma culta", que podem ser entendidas como os produtos culturais da Filosofia, Ciência e Li- 
teratura. Assemelha-se com a reivindicação de Antonio Cândido (2004) ao direito à literatura como parte dos direitos humanos. De forma bem simplista é dizer que apropriar-se da norma culta levará a pessoa para um lugar social melhor, por isso deve ser direito de todos, para que todos tenham acesso às mesmas condições e possam "evoluir" socialmente. Não cabe nesse ensaio refazer essa discussão sociológica, no entanto, considero que esta visão é ideológica e está estandardizada no senso comum.

No entanto, a argumentação com esse viés do direito, no caso específico da revista Veja a respeito da "norma culta", acaba tropeçando no que defende em vários pontos. Se for verdade que a "norma culta" dá acesso ao entendimento mais apurado da ciência, tem-se um problema no caso Veja versus MEC. Considerando que os escritores da Veja são os representantes da norma culta, eles demonstraram muitas dificuldades semânticas para interpretar o livro didático, argumentando que o livro faz algo que não faz, como pregar que não se deve ensinar a "norma culta". O texto principal generaliza a questão, afirmando que crianças serão ensinadas por esse viés, quando o livro didático é destinado para jovens e adultos. Outro problema diz respeito ao acesso à Ciência, no caso da Sociolinguística, que a revista também tropeçou no entendimento.

Por outro lado, partindo do pressuposto de leitura correta dos representantes da "norma culta", os escritores da Veja sabiam que tinham o poder de transformar em verdade uma não verdade, isto é, por isso afirmaram em vários momentos que o texto do livro didático afirmava algo que não afirmava. Se a crença de que a "norma culta" é capaz de fazer exatamente o que a revista apregoa, conclui-se, pois, que eles entenderam a proposta do livro, da Sociolinguística e também o argumento do MEC ao se defender. E decidiram pelo silêncio político e a uma estratégia de desqualificação a partir do senso comum estandardizado.
Um dos fragmentos mais emblemáticos dos três artigos para se demonstrar essa hipótese, está no trecho retirado da seção "Carta ao Leitor", o artigo que abre a discussão na revista:

A discussão arcana sobre o "falar popular" ocupa um escaninho secundário na sociolinguística e seria um enorme favor aos brasileiros que estudam e trabalham se nunca tivesse deixado seu porão acadêmico. Mas deixou, em prejuízo de alunos já tão pouco predispostos ao estudo da gramática e atolados em um sistema educacional que, ao final do ensino básico, produz $62 \%$ de jovens que mal sabem ler e $89 \%$ que não sabem fazer as operações aritméticas básicas (idem, p.14)

Primeiramente, afirma que a discussão da Sociolinguística sobre o "falar popular" é arcana, mesmo com um dos expoentes brasileiros apontados na revista, o professor Marcos Bagno, ter chegado à $52^{\mathrm{a}}$ edição do seu livro em 2009 com mais de 200 mil cópias vendidas exatamente sobre o conceito de "preconceito linguístico". Também afirma que essa abordagem ocupa o escaninho secundário na Sociolinguística e deveria continuar no porão acadêmico. O jornalista toma para si a discussão de uma ciência, a Sociolinguística, desqualificando-a, dando a entender que essa visão prejudicou alunos já sacrificados por um sistema de ensino deficitário. Dá-se tal poder à Sociolinguística na construção fraseológica que a própria construção diz que ela não tem. Ele se utiliza indiretamente da metáfora do alienígena ao dizer que a "discussão arcana" nem deveria ter deixado o "porão acadêmico". Seu discurso de desqualificação, em nome da vontade de verdade foucaultiana, tem como objetivo interditar outro discurso.

No caso brasileiro, o que está em jogo é o testemunho histórico do momento do embate entre a institucionalização da 
vontade de verdade de uma vertente da Sociolinguística a partir do MEC e a vontade de verdade já consolidada do que se denomina "norma culta" denunciada pela primeira vontade de verdade de discurso hegemônico. É o que Foucault diz:

Enfim, creio que essa vontade de verdade assim apoiada sobre um suporte e uma distribuição institucional tende a exercer sobre os outros discursos - estou sempre falando de nossa sociedade - uma espécie de pressão e como que um poder de coerção (FOUCAULT, 2009, p. 8)

No caso brasileiro a questão é a institucionalização que o MEC proporciona aos trechos que foram selecionados acima, tanto do texto do livro didático quanto do livro de Bagno sobre o poder da norma culta em detrimento da norma popular, por isso a indignação dos autores da revista sobre o MEC permitir tal "absurdo", isto é, a institucionalização. Por outro lado, a proposta de Bagno é a "democratização" linguística. Portanto, há uma disputa de poder em jogo. Enquanto a discussão estava no terreno acadêmico e não se ultrapassava essa linha, segundo a revista, não teria tanto problema. Mas ultrapassar a linha é disputar o poder, de quem detém a verdade sobre o assunto.

Podemos verificar a vontade de verdade do discurso foucaultiano do jornalista se nos distanciarmos e entendermos a função estrutural da língua (a metáfora do alienígena de forma positiva), para entender a manobra do jornalista em desqualificar exatamente o processo (usando indiretamente a metáfora do alienígena como crítica), o qual desvenda sua manobra. As paixões ficam tão acirradas neste momento que somente o distanciamento permite enxergar o recurso utilizado para interdição foucaultiana do discurso da Sociolinguística por causa da vontade de verdade de validação da "norma culta" como representante do "bom português".
E por que toda essa manobra é acalorada e cheia de paixões? Mais uma vez Foucault explica que as exclusões do discurso estão relacionadas ao desejo e ao poder. Quando a "norma culta", que poucos a dominam, torna-se um objeto de desejo de muitos, que não a dominam, esses poucos possuem um poder diante desses poucos que a desejam. Não é a toa que o jornalista afirma: "O pano de fundo dessa fraude intelectual é a concepção ideológica segundo a qual só o povo é detentor do verdadeiro conhecimento" (op. cit., p. 14). Eis aí desvendado o poder. E o autor continua na frase seguinte: "o lado perverso desse desvario é que, com isso, se justifica o não fornecimento, às pessoas que mais precisam deles, dos códigos que lhes permitiriam alcançar uma vida melhor". Eis aí revelado o desejo.

\section{CONSIDERAÇÕES FINAIS}

Pode-se perceber, nesta análise, que não está em discussão o "bom ou mal português". A escolha do MEC torna-se um discurso "perigoso", pois desvendados os estudos sociolingüísticos para aqueles que não os conhecem, esvazia-se o poder daqueles que os conhecem. A estratégia para a interdição é de desqualificação da autenticidade científica da Sociolinguística e não os estudos científicos em si.

Esse episódio relacionado ao MEC desvenda a disputa de discursos controversos, utilizando a estrutura da língua, para preservação de um lugar de poder de poucos, perpassado pelo desejo de muitos de obter esse lugar privilegiado, que legitima o lugar do poder. Enquanto essa disputa continua acirrando os ânimos, a língua continua destemidamente sua variação, até chegar a uma mudança no futuro, como sempre ocorreu na linha diacrônica de todas as línguas, como bem atestaria o alienígena. 


\section{Bibliografia:}

BAGNO, Marcos. Preconceito Linguístico. O que é, como se faz. São Paulo: Loyola, 1999.

BETTI, Renata ; LIMA, Roberta de Abreu. Os adversários do bom português. . IN: Veja. São Paulo: 25 de maio de 2011.

BRASIL. MINISTÉRIO DA EDUCAÇÃO. Haddad defende conteúdo e lembra que escolha é feita nas universidades. 31 de maio de 2011. Disponível em: http://portal.mec.gov.br/index.php?option=com_cont ent\&view=article\&id=16684:haddad-defende-conteudo-e-lembra-que-escolha-e-feita-nas-universidades\& catid=211\&ltemid=86. Acessado em 09 junho 2011.

CANDIDO, Antonio. O direito à literatura. IN: Diversos Escritos. São Paulo ; Rio de Janeiro: Duas cidades ; Ouro sobre Azul, 2004.

FOUCAULT, Michel. A Ordem do Discurso. Aula inaugural no College de France, pronunciada em 2 de dezembro de 1970. São Paulo: Edições Loyola, 2009.

ESCREVER é diferente de falar. IN: Por uma vida melhor. Disponível em <http://www.acaoeducativa. org.br/downloads/V6Cap1.pdf>. Acessado em 20 junho 2011.

HALL, Stuart. Estudos Culturais dois paradigmas. IN: Da Diáspora: identidades e mediações culturais. Belo Horizonte: Editora UFMG, 2009. p. 124-125. ILARI, Rodolfo. Linguística Românica. São Paulo: Ática, 1999.
LUFT, Lya. Chancela para a ignorância. IN: Veja. São Paulo: 25 de maio de 2011.

ORLANDI, Eni Pulcinelli. Terra à vista: discurso do confronto: velho e novo mundo. São Paulo ; Campinas, SP: Cortez ; Editora da Universidade Estadual de Campinas, 1990.

PRECONCEITO contra a Educação. IN: Veja. São Paulo: 25 maio, 2011.

SAUSSURE, Ferdinand de. Curso de Linguística Geral. São Paulo: Cultrix, 2006.

\footnotetext{
* Agradeço a bacharela e mestra em Línguística Claudia Dourado de Salces pela leitura e sugestões. Este ensaio foi realizado para o trabalho final da disciplina História e Teorias dos Estudos Culturais do Programa de Mestrado Acadêmico em Estudos Culturais da Escola de Artes, Ciências e Humanidades (EACH) da Universidade de São Paulo (USP).

. Bacharela em Linguística pela Universidade Estadual de Campinas (Unicamp) e mestranda do programa de Estudos Culturais da EACH-USP sob orientação de Profa. Dra. Graziela Serroni Perosa. Bolsista Capes.
${ }^{1}$ Para conhecer a obra organizada por seus alunos ver Saussure (2006).
${ }^{2}$ Os conceitos foucaultianos foram destacados em itáli- co nessa parte inicial.

Contato:

Adriana Santiago Rosa Dantas

-novadrica@gmail.com

Artigo recebido em Setembro de 2011

Artigo aprovado em Maio/2012 